\title{
ANTIMICROBIAL ACTIVITY OF SOME FOLK MEDICINAL PLANTS USED IN RAJASTHAN AGAINST SELECTED PATHOGENIC MICROORGANISMS
}

\author{
MAYA VERMA*, ASHWANI KUMAR \\ Kirori Mal College, New Delhiand Department of Botany, University of Rajasthan, Jaipur \\ Email: maya25verma@yahoo.com
}

Received: 27 Dec 2016, Revised and Accepted: 27 Mar 2017

\section{ABSTRACT}

Objective: To investigate the antibacterial efficacy of methanol extracts of leaves and roots of B. diffusa, Eclipta alba, Phyllanthus niruri and Ricinus communis.

Methods: The antimicrobial efficacy of methanol extracts of some medicinal plants was evaluated by agar well diffusion method against selected pathogenic bacterial strains. Gram+ve strains ( $S$. aureus, B. subtilis) were tested and Gram-ve strains tested were (E. coli, S. typhii and K. pneumoniae). Antifungal activity against was tested.

Results: B. diffusa and P. niruri leaf extract showed highest antibacterial activity against $S$. aureus and $S$. typhii. Leaf extract of $P$. niruri and R. communis showed highest antifungal activity against $A$. niger and $C$. albicans respectively

Conclusion: The methanolic leaf extracts of B. diffusa and P. niruri were highly active against S. aureus and S. typhii.

Keywords: Antibacterial, Medicinal plants, Plant extract

(C) 2017 The Authors. Published by Innovare Academic Sciences Pvt Ltd. This is an open access article under the CC BY license (http://creativecommons.org/licenses/by/4.0/]

DOI: http://dx.doi.org/10.22159/ijcpr.2017v9i3.19595

\section{INTRODUCTION}

Plants produce an incredible array of secondary metabolites and many of these have been developed into economically important products including; oils, gums, resins, tannins, rubber, waxes, pigments, flavors, fragrances, surfactants, preservatives, pesticides, and pharmaceuticals [1]. Thus medicinal plants are under tremendous pressure all across the globe, especially in India. More than $90 \%$ of the medicinal plants for herbal industries in India and for export are drawn from the natural habitats thus challenging their existence [2, 3]. The structure of flavonoid compounds is a key determinant of their radical scavenging and metal chelating activity and this is referred to as structure-activity relationships [4]. Historically plants have provided a good source of anti-infective agent $[5,6]$. Medicinal plants are finding their way into pharmaceuticals, nutraceuticals, cosmetics and food supplements. There is a continuous and urgent need to discover new antimicrobial compounds with diverse chemical structures and novel mechanism of action because there have been an alarming increase in the incidence of new and re-emerging infectious diseases [7]. Natural products of higher plants may give a new source of antimicrobial agents with the possibly novel mechanism of action. Contrary to the synthetic drugs, antimicrobial of plant origin not associated with many side effects and have an enormous therapeutic potential to heal many infectious diseases [8]. Use of traditional medicine among the tribal local people and medicinal healers (hakims) is a significant part of Rajasthan's tradition and it is widely practiced till date.

Eclipta alba (Linn.) Hassk., is commonly known as Bhringaraj, commonly used for the treatment of gastrointestinal disorders, respiratory tract disorders (including asthma), fever, hair loss and greying of hair, liver disorders (including jaundice), skin disorders, spleen enlargement, and cuts and wounds. Pharmacological activities of plant extracts have revealed anticancer, hepatoprotective, anti-inflammatory, and antimicrobial properties [9]. $B$. diffusa L. (Nyctaginaceae) fresh or dried is the source of the drug punarnava which is official in Indian Pharmacopoeia as a diuretic. The plant is bitter, astringent, cooling, anthelmintic, diuretic, aphrodisiac, cardiac stimulant, diaphoretic, emetic, expectorant, anti-inflammatory, febrifuge and laxative besides being an active ingredient as a tonic $[10,11]$. It is useful in all types of inflammation, strangury, leucorrhoea, lumbago, myalgia, cardiac disorders, jaundice, anaemia, dyspepsia, constipation, cough, bronchitis and general debility, dyspepsia,oedema, jaundice, cough, hemorrhoids, pulmonary cavitations, anaemia, enlargement of spleen, abdominal pain, abdominal tumours, cancers $[12,13]$ and acts as an anti stress agent.

Phyllanthus niruri Linn. Belongs to Euphorbiaceae is often used in the traditional system of medicine for a variety of ailments including dropsy, diabetes, jaundice, asthma and bronchial infections [2]. In the Ayurvedic system of medicine, it is used in problems of the stomach, genitourinary system, liver,kidney and spleen. It is bitter, astringent, stomachic, diuretic, febrifuge and antiseptic. The whole plant is used in gonorrhoea, menorrhagia and other genital affections [14]. Ricinus communis Linn belongs to family Euphorbiaceae, popularly known as 'castor plant'. In the Indian system of medicine, the leaf, root and seed oil of this plant have been used for the treatment of inflammation and liver disorders. The plant has been found to be useful in hepatoprotective [15], anti filarial [16], antioxidant [17], antiasthmatic [18] and antimicrobial [19] activities. Roots of this plant showed anti-inflammatory and free radical scavenging, anti-fertility, antidiabetic, and antimicrobial properties.

\section{MATERIALS AND METHODS}

Collection of plant material

Fresh plants were collected from regional areas of Jaipur and authenticated by taxonomist the leaves were shade dried then coarsely powdered.

\section{Solvent extraction}

The dried leaves were powdered with the help of waring blender then powder was filled in a thimble and extracted successively with methanol solvent in a soxhlet extractor for $48 \mathrm{~h}$. The crude extracts were concentrated using vacuum evaporator.

\section{Antimicrobial screening}

All bacterial strains of (S. aureus, B. subtilis, E. coli, S. typhii and K. pneumoniae), were obtained from S. M. S. Medical college and fungal 
strains (A. niger, C. albicans, F. oxysporum) Microbiology lab, Deptt of botany, university of Rajasthan, Jaipur respectively. The bacteria were maintained on nutrient broth (NB) at $37^{\circ} \mathrm{C}$ and fungus were maintained on potato dextrose agar (PDA) at $28^{\circ} \mathrm{C}$.

\section{Preparation of inoculum}

The gram +ve (S. aureus, B. subtilis) and gram -ve bacteria (E. coli, $S$. typhii and K. pneumoniae) were incubated in nutrient broth in a rotary shaker at $37^{\circ} \mathrm{C}$, centrifuged at $10,000 \mathrm{rpm}$ for $5 \mathrm{~min}$, then pellet was suspended in double distilled water and cell density was standardized spectrophotometrically $\left(\mathrm{A}_{610} \mathrm{~nm}\right)$. The fungal inoculum was prepared from 6 to $12 \mathrm{~d}$ old culture grown on PDA medium. Then petri dishes were flodded with 5 to $10 \mathrm{ml}$ of distilled water and the conidia were scraped using a sterile spatula. The spore density of each fungus was adjusted with a spectrophotometer $\left(A_{595} \mathrm{~nm}\right)$ to obtain a final concentration of $10^{5} \mathrm{CFU} / \mathrm{ml}$.

\section{Anti-bacterial activity}

The antibacterial activity of the extracts was determined by the disc diffusion method. Different concentration of the extracts (100 $\mu \mathrm{g} / \mathrm{ml}$ ) was prepared by reconstituting with methanol. The test microorganisms were seeded into the respective medium by spread plate method $10 \mu \mathrm{l}\left(10^{6} \mathrm{CFU} / \mathrm{ml}\right)$ with the $24 \mathrm{~h}$ cultures of bacteria grown in nutrient broth. After solidification filter paper discs of Whatmann no. 1 (6 $\mathrm{mm}$ diameter) were impregnated with the extracts were placed on test organism-seeded plates. These bacterial species (S. aureus, B. subtilis, E. coli, S. typhii and K. pneumoniae) were used for the antibacterial test. Streptomycin $(10 \mu \mathrm{g} / \mathrm{ml})$ used as positive control, methanol solvent $(100 \mu \mathrm{g} / \mathrm{ml})$ used as negative control. The plates were incubated at $37^{\circ} \mathrm{C}$ for $24 \mathrm{~h}$. The diameter of the inhibition zones was measured in $\mathrm{mm}$.

\section{The anti-fungal activity}

The antifungal activity was tested by disc diffusion method. The potato dextrose agar plates were inoculated with each fungal culture (10 d old) by point inoculation. The filter paper discs $(6 \mathrm{~mm}$ diameter) impregnated with $100 \mu \mathrm{g} / \mathrm{ml}$ concentrations of the extracts were placed on test organism-seeded plates. Methanol was used to dissolve the extract and was completely evaporated before application on test organism-seeded plates. Black discs impregnated with methanol followed by drying off was used as negative control and Nystatin $(10 \mu \mathrm{g} / \mathrm{ml})$ used as positive control. The activity was determined after $72 \mathrm{~h}$ of incubation at $28{ }^{\circ} \mathrm{C}$. The diameter of inhibition zones were measured in $\mathrm{mm}$.

\section{Statistical analysis}

The data of all the parameters were statistically analyzed (statistical software used Minitab 14-state college, PA, USA) and zone of inhibition diameter values are expressed as Mean Diameter \pm SEM $(n=3)$

\section{RESULTS AND DISCUSSION}

Table 1 summarizes the microbial growth inhibition of methanol extract of B. diffusa, E. alba, P. niruri and $R$. communis against selected bacterial species. Methanolic leaf extract of $B$. diffusa showed significant activity against $S$. aureus, $B$. subtilis around 14 $\mathrm{mm}$. The highest antibacterial activity of $19 \mathrm{~mm}$ in $S$. aureus and least activity recorded in $K$. pneumoniae measured $10 \mathrm{~mm}$. Leaf extract of $B$. diffusa exhibited the highest activity against $S$. aureus and lowest in E. coli.e. alba leaf extract possessed maximum activity against $S$. aureus $(17 \mathrm{~mm})$ and $15 \mathrm{~mm}$ against $S$. typhii and $K$. pneumoniae. Bark/root extract of this plant showed highest inhibitory activity against $E$. coli and B. subtilis and least activity observed in S. typhii. P. niruri leaf extract showed a similar zone of inhibition against $S$. aureus and $S$. typhii $(18 \mathrm{~mm})$. Bark and root extract of $P$. niruri showed varied activity in the zone of inhibition from 10-16 mm against all the tested bacteria. Leaf and root/bark extract of $R$. communis showed almost similar antibacterial activity against all the tested baceteria. Leaf extract of $R$. communis showed highest antibacterial activity against $S$. aureus $(18 \mathrm{~mm})$ and least activity against $E$. coli and $K$. pneumoniae $(14 \mathrm{~mm})$. Bark root extract of this plant showed significant activity against $S$. aureus and $B$. subtilis (14 $\mathrm{mm}$ ) and least against $S$. typhii. The root and leaf extract of B. diffusa, E. alba, P. niruri and R. communis showed significant activity against these bacterial species. Leaf extract showed significant antibacterial activity when compared with bark root extract of all the tested plant extracts. Bark root extract of all medicinal plants extract was almost similar or higher activity when compared with Streptomycin antibiotic.

Antifungal activity of these plant leaf extracts showed significant activity when compared with bark or root extract (table 2). B. diffusa bark and leaf extract showed antifungal activity against A,niger $(10$ $\mathrm{mm}$ ) and $11 \mathrm{~mm}$ respectively. Similar results were obtained with $E$. alba, $P$. niruri and $R$. communis. All these plants showed less antifungal activity when compared with Nystatin antibiotic.

\section{CONCLUSION}

The current investigation proved the antibacterial efficacy of the plant against different bacterial strains and thus validating the traditional use of the plant against different diseases. Further research is needed toward isolation and identification of active principles present in the extracts which could possibly be exploited for pharmaceutical use.

\section{CONFLICT OF INTERESTS}

\section{Declare none}

\section{REFERENCES}

1. Singh G, Kumar P. Extraction and antimicrobial activity of alkaloids of E. hirta. and Padma Kumar. J Pharm Res 2011;4:1228-30.

2. Parivuguna V, Gnanaprabha, Dhanabalan R, Doss A. Antimicrobial properties and phytochemical constituents of Rhoeo discolor Hance. Ethnological leaflets 2008;12:841-5.

3. Raven PH, Evert, Eichhorn SE. Biology of plants. WH Freeman and Company: New York; 2005.

4. Hussain J, Khan AL, Rehman N, Zainullah, Hussain ST, Khan F, et al. Proximate and nutrient analysis of selected medicinal plant species of Pakistan. Pakistan J Nut 2009;8:620-4.

5. Faza SS, Singla RK. Review on the pharmacognostical and pharmacological characterization of Apium graveolens Linn. Indo Global J Pharm Sci 2012;2:36-42.

6. Balasundaram N, Sundram, Samman S. Phenolic compounds in plants and agri-industrial by-products: Antioxidant activity, occurrence, and potential uses. Food Chem 2006;99:199-203.

7. Erdemeier CAJ, Jr Cinal J, Ranenan H, Doerr HWA, Biber A, Koch E. Antiviral and antiphlogistic activities of Hemmalis virginiana bark. Planta Med 1996;62:241-5

8. Abo KA, Adeyemiand AA, Adeite DA. Ethnobotanical survey of plants used in the treatment of infertility and sexually transmitted diseases in South-West Nigeria. Afr J Med Sci 2000;29:325-7.

9. Khare CP. Indian Medicinal Plants: An Illustrated Dictionary, Springer, Berlin, Germany; 2007.

10. Prajapati ND, Purohit SS, Sharma AK, Kumar T. A handbook of Medicinal Plants-a complete source book, India; 2004.

11. Mudgal V. Comparative studies on the anti-inflammatory and diuretic action with different parts of the plant Boerhaavia diffusa Linn. (Punarnava). J Res Ind Med 1974;9:57-9.

12. Mudgal V. Studies on medicinal properties of Convolvulus pluricaulis and Boerhaavia diffusa. Planta Med 1975;28:62-8.

13. Girach RD, Aminuddin, Singh VK. Notable plants in ethnomedicine of Jajpur District, Orissa, India. In: Recent Progresses in Medicinal Plants. Govil JN. Editors. Vol. 14. Biopharmaceuticals; 2006. p. 495-501.

14. Foo LY, Wong H. Phyllanthusiin D, unusual hydrolysable tannin from phyllanthus niruri. Phytochemistry 1992;31:711-3.

15. Padmapriya B, Leema MCE, Kumar AP, Muhammad Ilyas MH, Rajeswari T. Antihepatotoxicity of ricinus communis (L.) against ketoconazole-induced hepatic damage. Adv Biol Res 2012;6:30-6.

16. Shanmugapriya R, Ramanathan T. Antifilarial activity of seed extracts of Ricinus communis against Brugia malayi. J Pharm Res 2012;5:1448-50.

17. Singh PP, Ambika, Chauhan SMS. Activity guided isolation of antioxidants from the leaves of ricinus communis L. Food Chem 2009;114:1069-72. 
18. Taur DJ, Patil RY. Antiasthmatic activity of Ricinus communis L. roots. Asian Pacific J Trop Biomed 2011;1:S13-S16.

19. Jombo GTA, Enenebeaku MNO. Antibacterial profile of fermented seed extracts of Ricinus communis: findings from a preliminary analysis. Niger J Physiol Sci 2008;23:55-9.

\section{How to cite this article}

- Maya Verma, Ashwani Kumar. Antimicrobial activity of some folk medicinal plants used in rajasthan against selected pathogenic microorganisms. Int J Curr Pharm Res 2017;9(3):84-86. 